
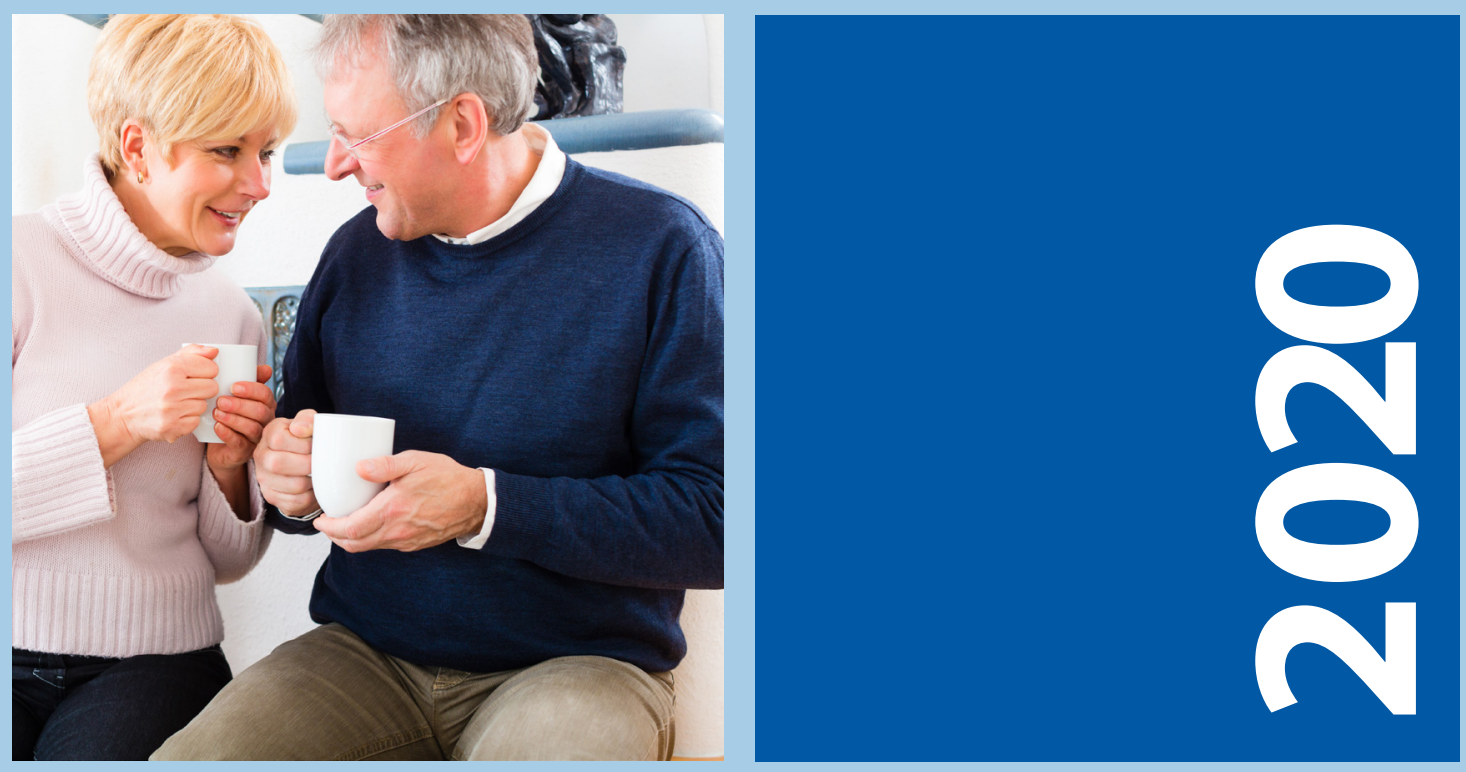

High-risk categories for COVID-19 and their distribution by county in Republic of Ireland-evidence from the TILDA study

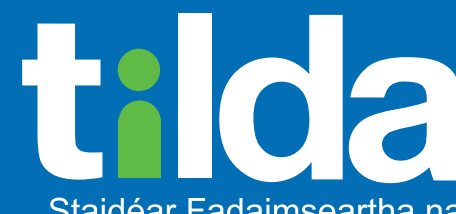

Staidéar Fadaimseartha na hÉireann um Dhul in Aois

The Irish Longitudinal Study on Ageing 


\section{High-risk categories for COVID-19 and their distribution by county in Republic of Ireland-evidence from the TILDA study}

Belinda Hernández, Donal Sexton, Frank Moriarty, Niall Cosgrave, Aisling O'Halloran, Christine McGarrigle, Siobhan Scarlett, Rose Anne Kenny 
Copyright (C) The Irish Longitudinal Study on Ageing 2020

The Irish Longitudinal Study on Ageing

Trinity College Dublin

Dublin 2

Tel: +35318962509

Email: tilda@tcd.ie

Website: www.tilda.ie

ISBN: 978-1-907894-28-2

https://www.doi.org/10.38018/TildaRe.2020-03 


\section{Acknowledgements}

We would like to acknowledge the vision and commitment of our study funders, the Department of Health, the Health Research Board, Science Foundation Ireland, The Atlantic Philanthropies, and Irish Life plc. We would like to state that any views expressed in this report are not necessarily those of the Department of Health or of the Minister for Health. We would also like to thank the TILDA participants without whom this research would not be possible. 


\section{Contents}

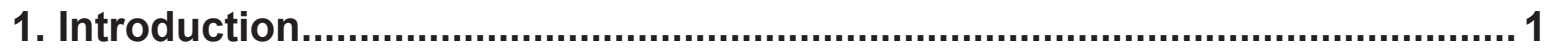

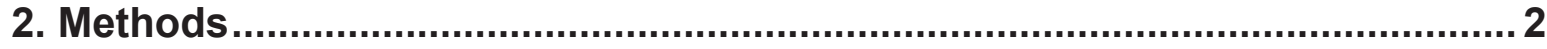

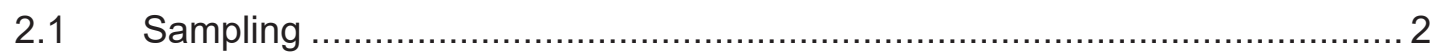

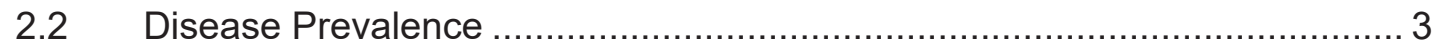

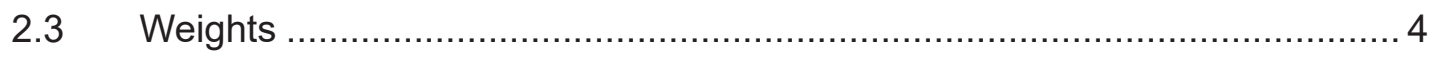

3. National Disease Prevalence and Comorbidities ........................................ 5

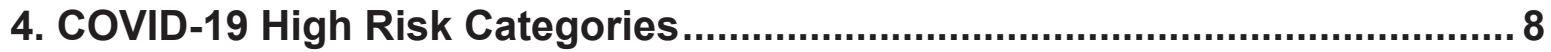

4.1 Chronic Lung Disease or Asthma .......................................................... 9

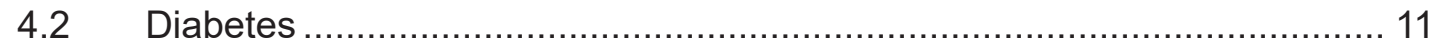

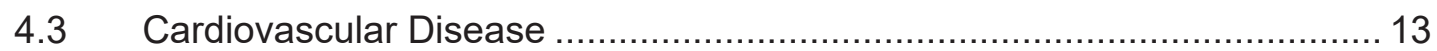

$4.4 \quad$ Diabetes and Cardiovascular Disease ................................................... 15

4.5 Ischaemic Heart Disease (Myocardial Infarction or angina)....................... 17

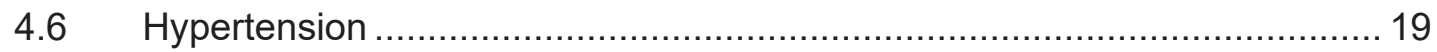

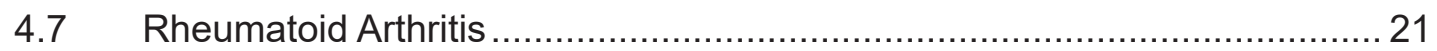

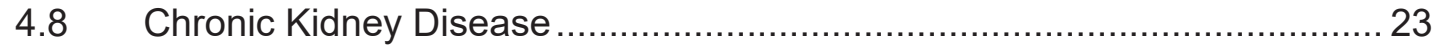

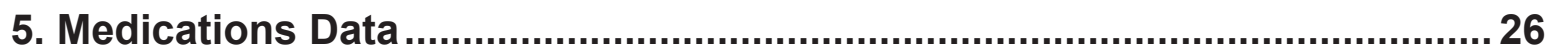

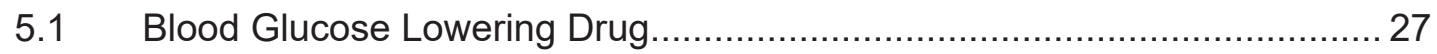

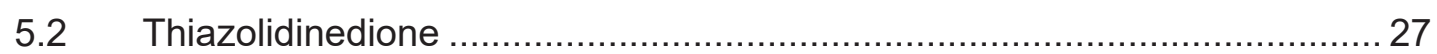

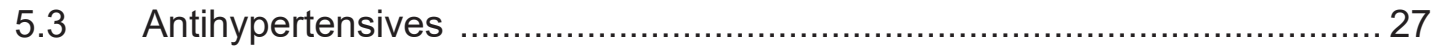

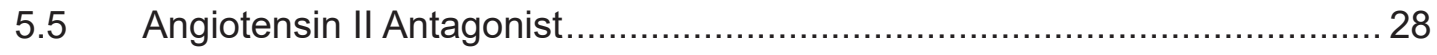

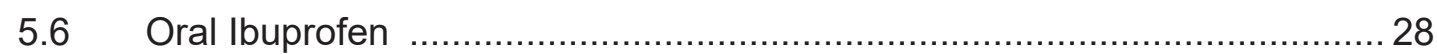

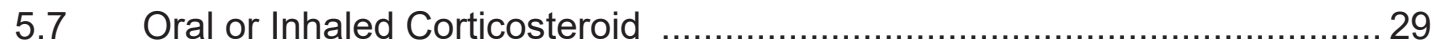

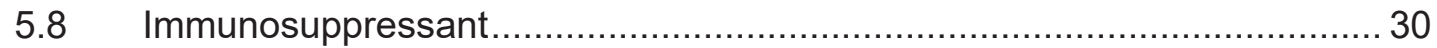

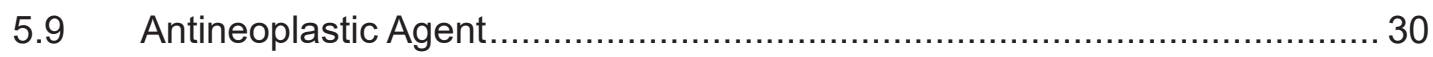

5.10 Topical Corticosteroid ................................................................... 30

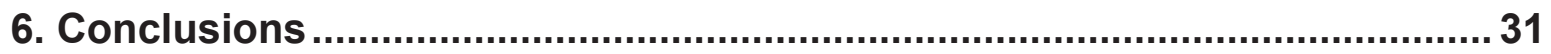

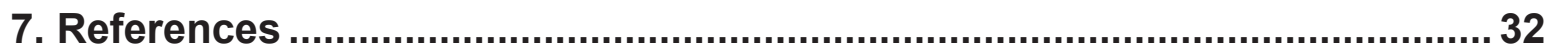




\section{COVID-19 HIGH RISK GROUPS}

MULTIMORBIDITY IN IRELAND

\begin{tabular}{l|c|c|c|c|c} 
& Hypertension & $\begin{array}{c}\text { Diabetes } \\
\text { Mellitus }\end{array}$ & $\begin{array}{c}\text { Chronic } \\
\text { Kidney } \\
\text { Disease }\end{array}$ & $\begin{array}{c}\text { Ischaemic } \\
\text { Heart } \\
\text { Disease }\end{array}$ & $\begin{array}{c}\text { Chronic Lung } \\
\text { Disease } \\
\text { or Asthma }\end{array}$ \\
\hline $\mathbf{5 0}$ years & $\mathbf{7 4 9 , 9 0 0}$ & 182,800 & 128,600 & 161,600 & 265,000 \\
\hline $\mathbf{7 0}$ years & 260,400 & 63,400 & 36,500 & 70,000 & 80,000 \\
\hline
\end{tabular}

COMORBIDITIES (WITH ESTIMATED POPULATION NUMBERS)

30

20

The Irish Longitudinal

Study on Ageing

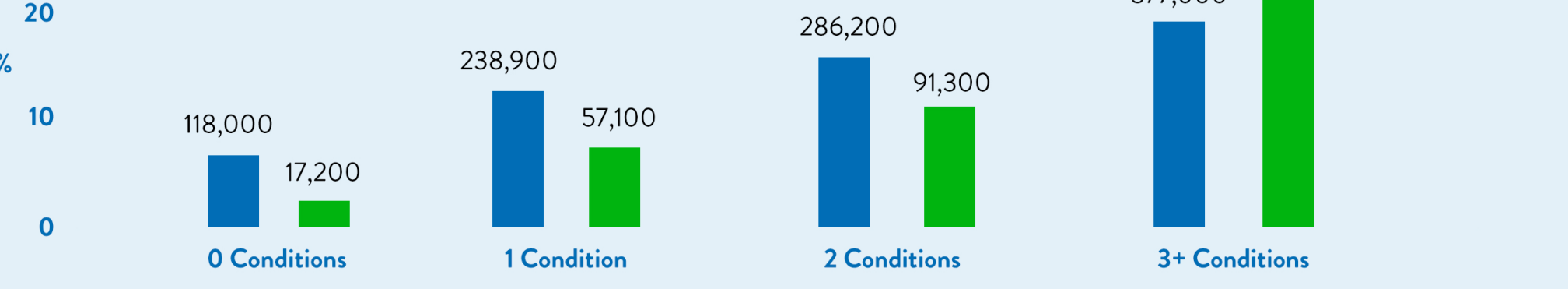

Number of Comorbidities

\section{MEDICATION USAGE LINKED TO POSSIBLE HIGH RISK FOR COVID-19}
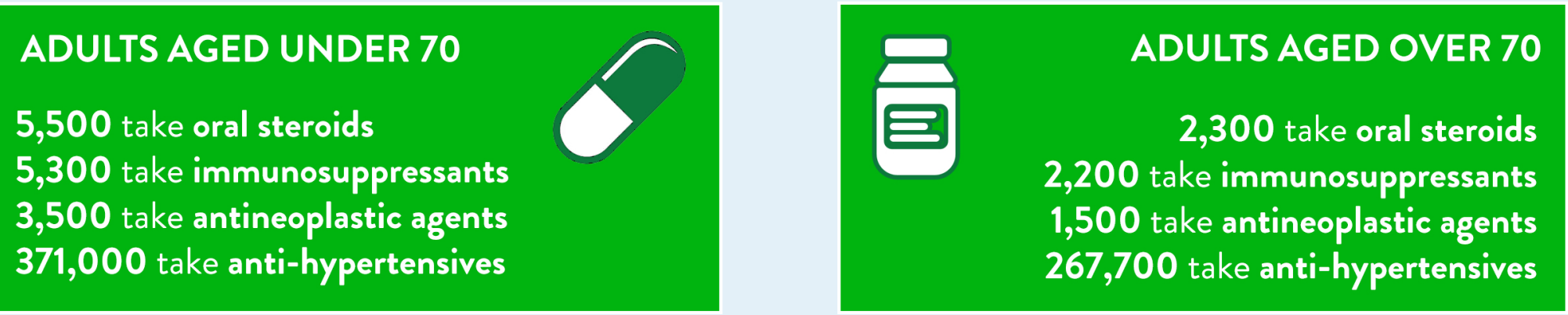

\section{For more information please visit www.tilda.ie Supported by

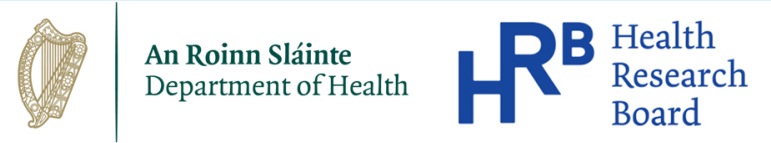 \\ Department of Health

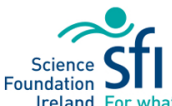 \\ Ireland For what's next

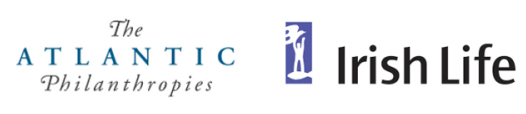




\section{Key Message}

Older persons and those with pre-existing chronic conditions are most likely to experience severe consequences from COVID-19. Because immune defences decline and chronic diseases rise with age, people aged 70 and older are at particularly high risk. The purpose of the report is to raise awareness of how common these high-risk groups are, nationally and at a county level, and how many people are at highest risk, i.e. have 3 or more chronic conditions.

\section{Key Findings}

- Almost 750,000 adults have hypertension (over $50 \%$ )

- Over 308,000 adults have asthma or chronic lung disease $(20 \%)$

- 183,000 adults have diabetes mellitus $(13 \%)$

- 129,000 adults have chronic kidney disease $(10 \%)$

- 167,500 adults have past or present cancer $(12 \%)$

- 638,000 adults live with three or more chronic diseases

- Over $30 \%$ of over 70 s live with three or more chronic diseases 


\section{Introduction}

This report will expand on a previous report on the estimated number of people in Ireland (by age and sex) who have diseases, poor health behaviours, multi morbidity and take possible at-risk medications [1] for COVID 19.

This report will show the estimated number of people over 50 in Ireland (and also by county and age brackets) who have diabetes, cardiovascular disease, ischaemic heart disease, lung disease or asthma, rheumatoid arthritis, chronic kidney disease and a history of smoking; all of which are medical conditions/behaviours suspected to be risk factors for more severe symptoms of COVID19. We will also provide data for over 70s and population estimates for medication usage linked to underlying conditions related to immune modulation and possible high risk for COVID19.

This data should assist policy makers to prepare for likely numbers of high-risk patients who will require additional community and hospital support. By estimating county-level numbers, we hope to further guide health service projections for need 


\section{Methods}

\section{$2.1 \quad$ Sampling}

Sampling for the first wave of TILDA was conducted using the RANSAM random sampling procedure [ 2,3$]$, with the Irish Geodirectory as a sampling frame. The Geodirectory is a complete listing of all residential addresses in the Republic of Ireland recorded by the Irish Postal Service (An Post) [4]. The addresses sampled were selected by first grouping addresses into clusters, based on District Electoral Divisions, then a number of clusters were randomly selected, and finally, 50 addresses were randomly selected from each cluster [2]. The final sample was of 8,174 individuals aged 50 and over, from 6,279 households, as well as 330 partners aged under 50 (young partners) (total $=8,504$ ). This constituted a $62 \%$ response rate for households with an eligible participant. Wave 1 interviews were completed between October 2009 and February 2011. Data were collected through three different formats: Computer Assisted Personal Interview (CAPI), SelfCompletion Questionnaire (SCQ), and Health Assessment.

All participants at each wave completed a CAPI interview. CAPI interviews were completed in the participant's own home by a trained social interviewer and included items on the participant's health, economic and social circumstances, as well as some cognitive measures. All participants were invited to complete a health assessment at Waves 1 and 3 and forthcoming Wave 6. Detailed health assessments were not carried out at Waves 2, 4 and 5, but the participants completed some objective measures in these waves important for frailty. At Wave 1, participants were invited to attend a dedicated health centre. Participants who preferred not to travel to attend a health assessment due to mobility or other issues were offered a health assessment at home. Home health assessments measured a reduced number of health measures due to the practicalities of completing the assessment at home. All health assessments were carried out by trained research nurses, and included anthropometric measures such as height and weight, physical function measures such as Timed-Up-and-Go and grip strength, detailed cardiovascular, mood and cognitive measures. The in-centre health assessment also collected more detailed measures of cardiovascular, bone, and eye health and other senses (Cronin et al., 2013). During Wave 1 , a total of 5,894 over 50 s participants completed a health assessment (72.1\%), 860 of which completed a health assessment at home. 


\subsection{Disease Prevalence}

For estimates of diseases and comorbidity prevalence, all numbers are calculated based on participants having a history of the disease, not just disease incidence at Wave 5 i.e. we counted disease as being present if the participant reported ever having any of the above medical conditions in any of the TILDA waves (2009-2018) not only if they reported it in 2018. To do this, we included data from all five waves of TILDA and counted disease as being present if a participant reported having the disease in any of the five waves and didn't later dispute having the disease at a later wave. The reason for this is that many participants confuse being cured of a disease and having a disease under control (when they are asked if they have ever been diagnosed with the conditions above, many will report no, as their condition is under control, even though they previously reported having the condition). If they report a condition at a given wave, they are asked to confirm it at the next wave and are given the opportunity to dispute the diagnosis. In all cases, our estimates have corrected for disputed/false diagnoses. In all cases population numbers have been rounded to the nearest 100 .

All estimates (unless otherwise indicated) are based on data from the most recent Wave 5 of TILDA (collected in 2018, $n=5,087$ participants) and population estimates are based on figures collected from the most recent 2016 Census data (which reported a total of $1,446,460$ people over 50 living in Ireland). Whereas the disease count we derived from the CAPI interview, information on chronic kidney disease was estimated from blood samples for creatine and consequently glomerular filtration rates. Hereafter denoted *. It should be noted that the TILDA sampling frame does not include people with dementia at baseline or people living in nursing homes, and so this data may slightly underestimate prevalence for the total population of older adults living in Ireland.

In many cases, the number of TILDA cases by county for each of the following conditions is very small, and so estimates have very wide confidence intervals and may not be reliable. This is even more true for the county by age estimates which in many cases may be associated with large error. Also, in all cases the estimated population numbers have been rounded to the nearest 100 and so table totals by county may not always tally to the country totals. In some cases, the number of cases sampled by TILDA when separated by age and county were so small that no estimate of the population prevalence could be made; such cases have been marked as NA. 


\subsection{Weights}

As stated, weights were used to make estimates relevant to the general population of over 50 s in Ireland. In this instance, longitudinal weights which account for participant attrition between Wave 1 and Wave 5 were used. To calculate these weights, the underlying probability of being included in the computer-assisted personal interview (CAPI) was multiplied by the reciprocal of the probability of participating in all five TILDA waves. This probability was calculated using a logistic regression with the following predictors: age, sex, education level, age, marital status, geographic location, smoking status, health insurance, medications, socio-economic stratum, self-rated health, disabilities, depression, employment status, cardiovascular conditions, diabetes, vision, cognitive status and whether a person has wrist or hip fractures. 


\section{National Disease Prevalence and Comorbidities}

Figure 1 and table 1 show the prevalence and estimated number is the population with each of the 16 medical conditions mentioned below. Chronic kidney disease was only measured at Wave 1 of TILDA (2009-2010) and so has not been included in the following estimates based on 2018 data. However, the national prevalence of chronic kidney disease (based on 2011 census) was $10.1 \%$ or 128,582 people.

The total list of underlying medical conditions from Wave 5 TILDA included life-time prevalence of any of the following 16 conditions:

- High Cholesterol

- Hypertension

- Arthritis (including osteoarthritis, or rheumatism)

- Osteoporosis, sometimes called thin or brittle bones

- Asthma

- Diabetes

- Cancer or a malignant tumour

- Thyroid Problems

- Chronic lung disease such as chronic bronchitis or emphysema

- Angina*

- A heart attack (incl. myocardial infarction or coronary thrombosis)*

- Varicose Ulcers (an ulcer due to varicose veins)

- Ministroke/TIA

- Stroke

- Congestive heart failure

- Cirrhosis, or serious liver damage

*ischaemic heart disease 
Figure 1. Percentage of population with each of the 16 medical conditions

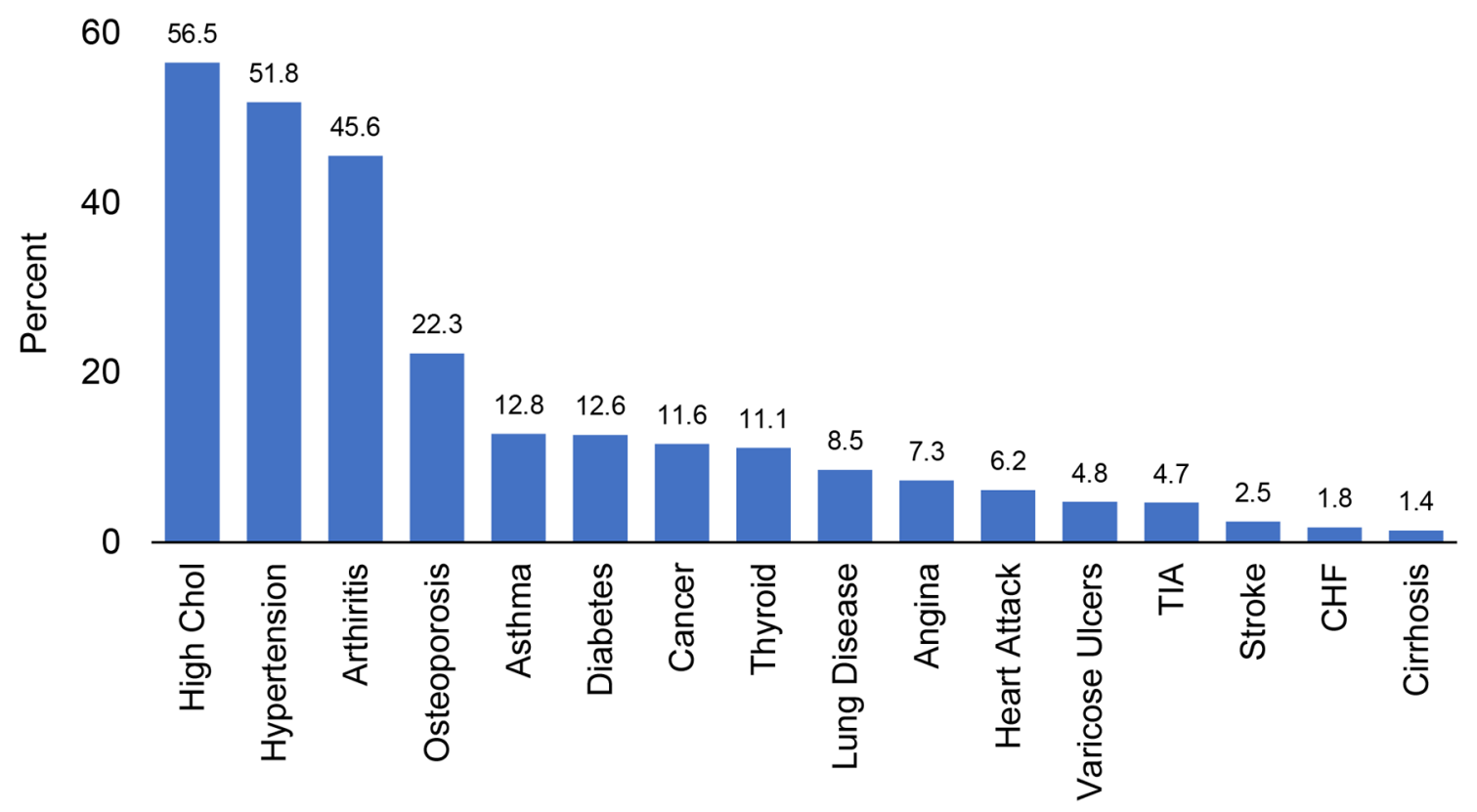

Table 1. Disease prevalence in TILDA and Population of over 50s in Ireland

\begin{tabular}{|l|c|c|c|}
\hline Medical Condition & $\begin{array}{c}\text { Number of } \\
\text { cases in } \\
\text { TILDA }\end{array}$ & $\begin{array}{c}\text { Estimated } \\
\text { Population } \\
\text { Prevalence \% }\end{array}$ & $\begin{array}{c}\text { Estimated } \\
\begin{array}{c}\text { Number in } \\
\text { Population } \\
\text { (n=1,446,460) }\end{array}\end{array}$ \\
\hline $\begin{array}{l}\text { Asthma } \\
\begin{array}{l}\text { Chronic lung disease such as chronic bronchitis } \\
\text { or emphysema }\end{array}\end{array}$ & 402 & 12.79 & 185002 \\
\hline Hypertension & 2589 & 51.84 & 123383 \\
\hline Diabetes & 612 & 12.64 & 182833 \\
\hline Angina & 337 & 7.27 & 105158 \\
\hline $\begin{array}{l}\text { A heart attack (incl. myocardial infarction or } \\
\text { coronary thrombosis) }\end{array}$ & 295 & 6.16 & 89102 \\
\hline Congestive heart failure & 83 & 1.75 & 25313 \\
\hline Cancer or a malignant tumour & 612 & 11.58 & 167500 \\
\hline Arthritis (including osteoarthritis, or rheumatism) & 2256 & 45.55 & 658863 \\
\hline Osteoporosis, sometimes called thin or brittle & 1148 & 22.27 & 322127 \\
\hline bones & 592 & 11.11 & 160702 \\
\hline Thyroid Problems & 226 & 4.75 & 68707 \\
\hline Varicose Ulcers (an ulcer due to varicose veins) & 242 & 4.66 & 67405 \\
\hline Ministroke/TIA & 143 & 2.45 & 35438 \\
\hline A stroke (cerebral vascular disease) & 83 & 1.75 & 25313 \\
\hline Congestive heart failure & 3037 & 58.5 & 846179 \\
\hline High Cholesterol & 59 & 1.4 & 20250 \\
\hline Cirrhosis, or serious liver damage & 428 & 10.1 & 128582 \\
\hline Chronic Kidney Disease* & & & \\
\hline
\end{tabular}


Table 2 and figure 2 below show the breakdown of those with 0, 1, 2 and 3+ medical conditions for the under and over 70s in the Republic of Ireland.

Table 2. Estimated number in population of under and over 70 s with 0-3+ underlying medical conditions

\begin{tabular}{l|c|c|c}
\hline Number of Medical Conditions & $<70$ & $70+$ & Total \\
\hline 0 & 118026 & 17180 & 135200 \\
\hline 1 & 238907 & 57124 & 296000 \\
\hline 2 & 286240 & 91313 & 377600 \\
\hline $3+$ & 377029 & 260682 & 637700 \\
\hline
\end{tabular}

Figure 2. Percentage of population with $0-3+$ medical conditions (separated by age $<70,70+$ ).

30

30.1

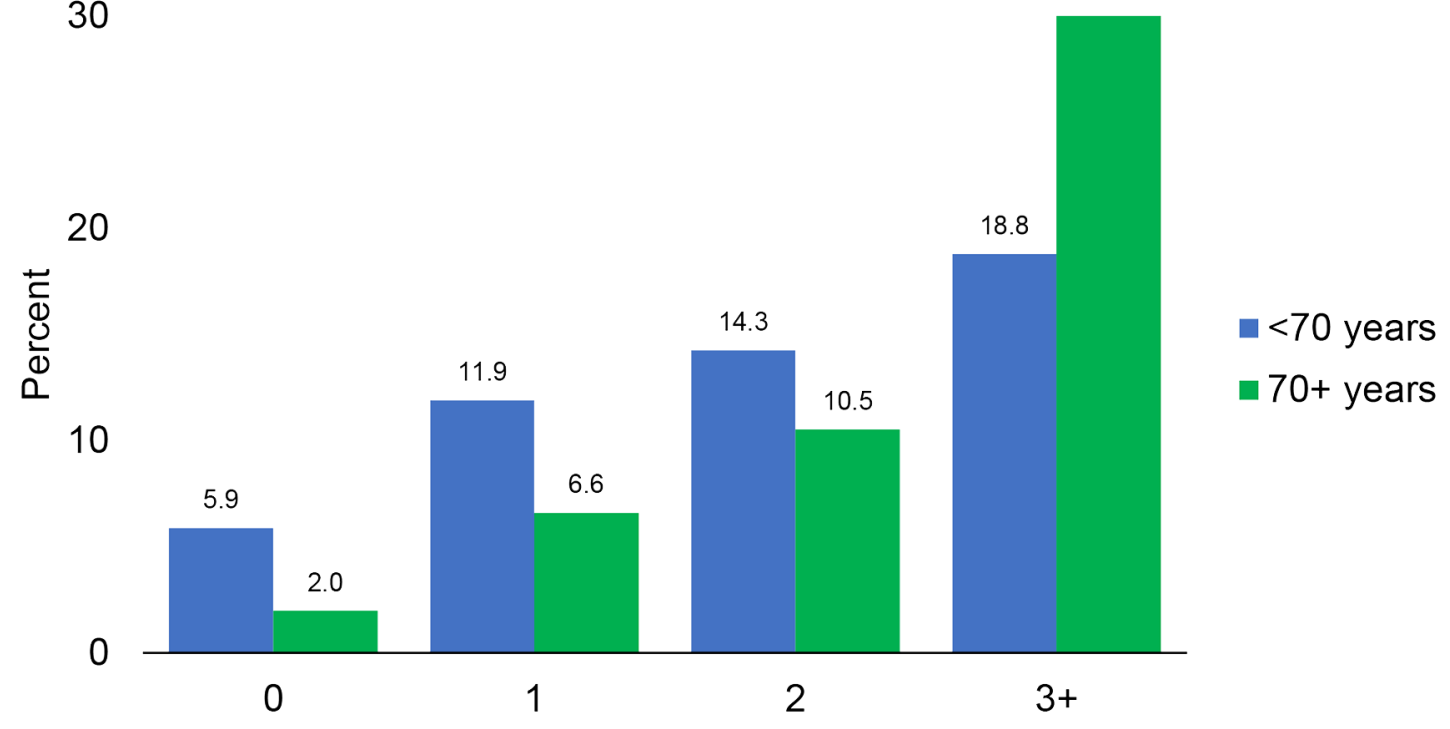




\section{COVID-19 High Risk Categories}

The remainder of this report will show the breakdown of lung disease or asthma, diabetes, cardiovascular disease, the co-occurrence of diabetes and cardiovascular disease, rheumatoid arthritis and smoking history at a country level and the distribution at county level (with estimated numbers of cases in the population). Given that recommendations for social isolation have focused on vulnerable cohorts, and instruction from Government on March 27th for 'cocooning' of those aged 70+, estimates have been shown for the under and over 70 s. 


\subsection{Chronic Lung Disease or Asthma}

The estimated total number of people aged $50+$ with either chronic lung disease or asthma in the Republic of Ireland is 264,702 (prevalence 18.3\%). Figure 2 shows the distribution of chronic lung disease prevalence by age. Table 2 shows the breakdown of number of cases in TILDA, the estimated prevalence (\%) in the population and the estimated number of cases of chronic lung disease in the population.

Table 3: Breakdown of number of cases in TILDA, the estimated prevalence (\%) in the population and the estimated number of cases of either lung disease or asthma in the population for under and over 70 s.

\begin{tabular}{|l|c|c|c|}
\hline Either Lung disease or asthma by Age & $50-69$ & $70+$ & TOTAL \\
\hline Number Cases in TILDA & 8 & 75 & 890 \\
\hline Estimated Prevalence in Population & NA & $1.98 \%$ & $18.30 \%$ \\
\hline Estimated Number of Cases in Population & NA & 28640 & 264702 \\
\hline
\end{tabular}

Note: The sum over age ranges may not equal total, due to slight inaccuracies in age estimates and rounding errors within age each age range

\subsubsection{Chronic Lung Disaease or Asthma by County}

Figure 3. Estimated population prevalence of lung disease or asthma within each county

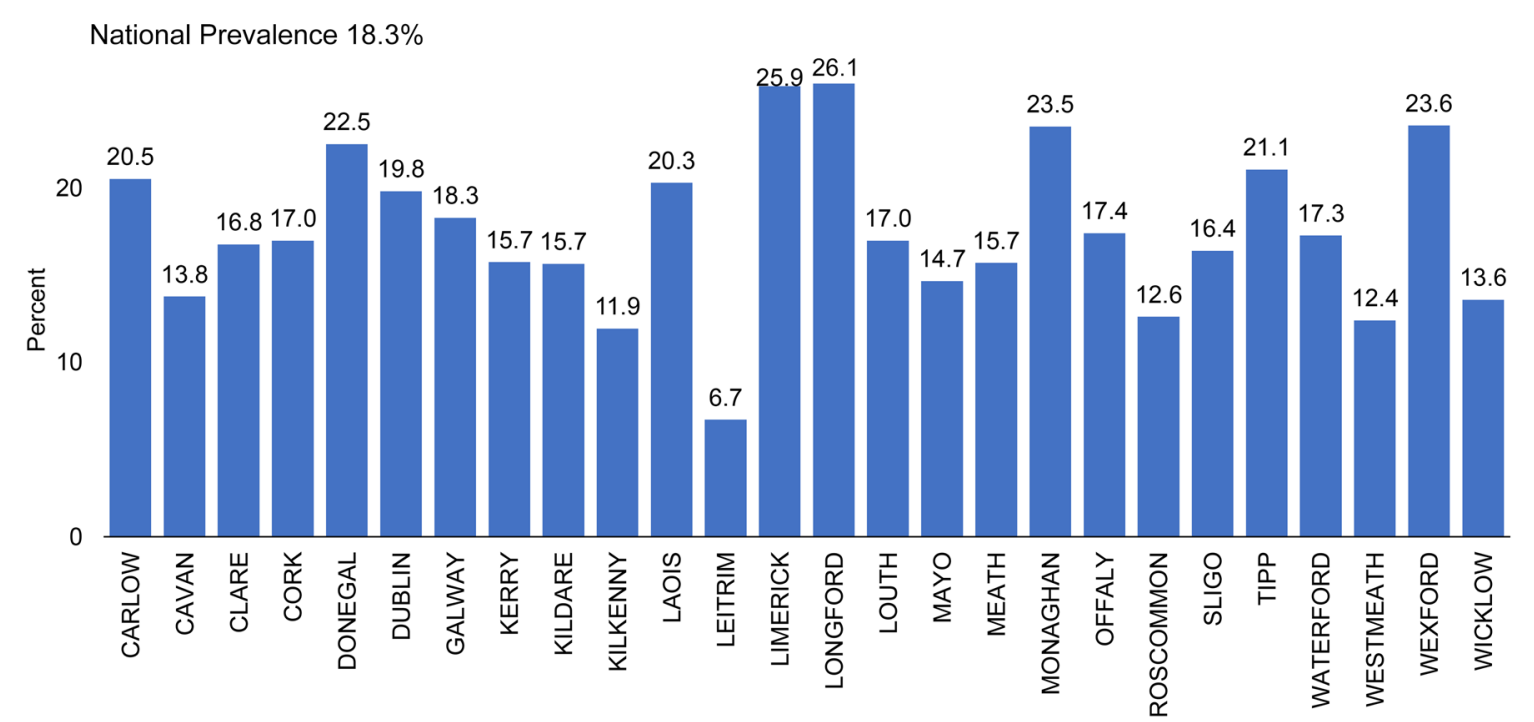


Table 4: Breakdown of number of cases with either lung disease or asthma in TILDA, the estimated prevalence (\%) within each county and the estimated number of cases either lung disease or asthma in the population by county to nearest 100.

\begin{tabular}{|c|c|c|c|}
\hline County & $\begin{array}{c}\text { Number } \\
\text { of TILDA } \\
\text { Cases }\end{array}$ & $\begin{array}{c}\text { County } \\
\text { Prevalence }\end{array}$ & $\begin{array}{l}\text { Estimated } \\
\text { Number in } \\
\text { Population }\end{array}$ \\
\hline CARLOW & 13 & $20.52 \%$ & 3500 \\
\hline CAVAN & 10 & $13.77 \%$ & 3300 \\
\hline CLARE & 22 & $16.76 \%$ & 6700 \\
\hline CORK & 97 & $16.98 \%$ & 28300 \\
\hline DONEGAL & 41 & $22.53 \%$ & 12000 \\
\hline DUBLIN & 225 & $19.81 \%$ & 74200 \\
\hline GALWAY & 50 & $18.29 \%$ & 14400 \\
\hline KERRY & 31 & $15.74 \%$ & 8500 \\
\hline KILDARE & 16 & $15.65 \%$ & 9000 \\
\hline KILKENNY & 16 & $11.93 \%$ & 3800 \\
\hline LAOIS & 12 & $20.30 \%$ & 4700 \\
\hline LEITRIM & 3 & $6.72 \%$ & 800 \\
\hline LIMERICK & 50 & $25.85 \%$ & 15800 \\
\hline LONGFORD & 11 & $26.05 \%$ & 3400 \\
\hline LOUTH & 14 & $16.99 \%$ & 6300 \\
\hline MAYO & 42 & $14.66 \%$ & 7100 \\
\hline MEATH & 29 & $15.70 \%$ & 8200 \\
\hline MONAGHAN & 20 & $23.54 \%$ & 4600 \\
\hline OFFALY & 16 & $17.41 \%$ & 4200 \\
\hline ROSCOMMON & 20 & $12.61 \%$ & 2900 \\
\hline SLIGO & 13 & $16.40 \%$ & 3800 \\
\hline TIPPERARY & 42 & $21.07 \%$ & 11400 \\
\hline WATERFORD & 19 & $17.26 \%$ & 6600 \\
\hline WESTMEATH & 11 & $12.40 \%$ & 3300 \\
\hline WEXFORD & 49 & $23.59 \%$ & 11600 \\
\hline WICKLOW & 18 & $13.58 \%$ & 6000 \\
\hline Total & 890 & $18.30 \%$ & 264400 \\
\hline
\end{tabular}

Note: County estimates may not add up exactly to the national total reported in other tables above as in some cases the number sampled within each county are so small that estimates may not be accurate. 


\subsection{Diabetes}

The estimated total number of people aged $50+$ with diabetes in the Republic of Ireland is 182,833 (prevalence 12.64\%). Figure 5 shows the distribution of diabetes prevalence by age. Table 7 shows the breakdown of number of cases in TILDA, the estimated prevalence $(\%)$ in the population and the estimated number of cases of diabetes in the population.

Table 5. Breakdown of number of cases in TILDA, the estimated prevalence (\%) in the population and the estimated number of cases of diabetes in the population for under and over 70s.

\begin{tabular}{|l|c|c|c|}
\hline Diabetes by Age & $50-69$ & $70+$ & TOTAL \\
\hline Number Cases in TILDA & 241 & 239 & 600 \\
\hline Estimated Prevalence in Population & $10.49 \%$ & $14.86 \%$ & $12.64 \%$ \\
\hline Estimated Number of Cases in Population & 107012 & 63353 & 182833 \\
\hline
\end{tabular}

Note: The sum over age ranges may not equal total, due to slight inaccuracies in age estimates and rounding errors within age each age range

\subsubsection{Diabetes by county}

The following plot shows the distribution of diabetes cases across Ireland. NOTE: The percentages shown are the total percent by county not the percentage of cases within each county i.e. if you add up the percentages across all counties in Ireland it adds up to the total country prevalence of $12.64 \%$.

Figure 4. Diabetes distribution by county

National Prevalence 12.64\%

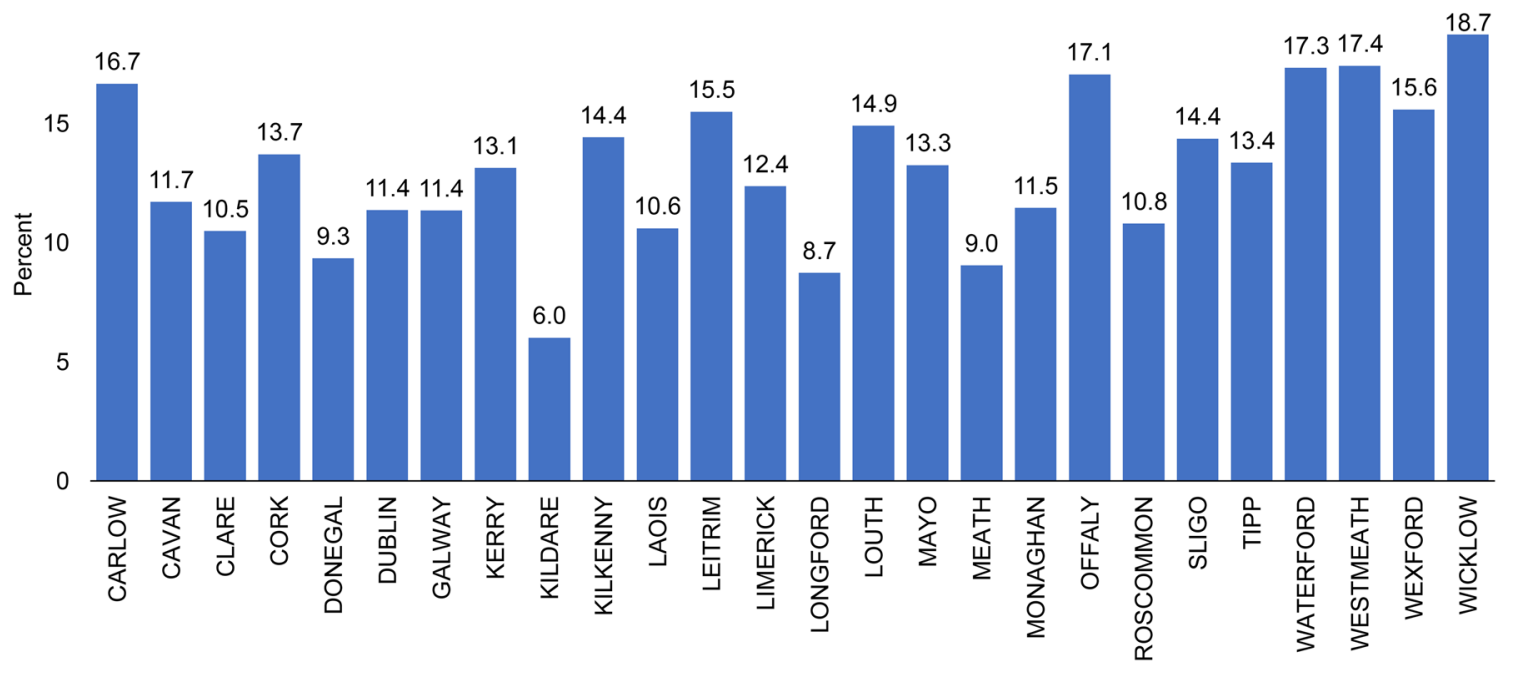


The table below shows the number of cases with diabetes in Tilda, the estimated population prevalence and estimated number in the population by county.

Table 6. Breakdown of number of cases with diabetes in TILDA, the estimated prevalence (\%) within each county and the estimated number of cases of diabetes in the population by county to nearest 100 .

\begin{tabular}{|c|c|c|c|}
\hline County & $\begin{array}{c}\text { Number } \\
\text { of TILDA } \\
\text { Cases }\end{array}$ & $\begin{array}{c}\text { County } \\
\text { Prevalence }\end{array}$ & $\begin{array}{l}\text { Estimated } \\
\text { Number in } \\
\text { Population }\end{array}$ \\
\hline CARLOW & 8 & $16.68 \%$ & 2800 \\
\hline CAVAN & 6 & $11.71 \%$ & 2800 \\
\hline CLARE & 10 & $10.48 \%$ & 4200 \\
\hline CORK & 61 & $13.71 \%$ & 22900 \\
\hline DONEGAL & 22 & $9.34 \%$ & 5000 \\
\hline DUBLIN & 138 & $11.36 \%$ & 42500 \\
\hline GALWAY & 28 & $11.35 \%$ & 8900 \\
\hline KERRY & 24 & $13.14 \%$ & 7100 \\
\hline KILDARE & 10 & $6.01 \%$ & 3400 \\
\hline KILKENNY & 13 & $14.42 \%$ & 4600 \\
\hline LAOIS & 6 & $10.60 \%$ & 2500 \\
\hline LEITRIM & 4 & $15.50 \%$ & 1800 \\
\hline LIMERICK & 25 & $12.37 \%$ & 7600 \\
\hline LONGFORD & 4 & $8.73 \%$ & 1100 \\
\hline LOUTH & 13 & $14.91 \%$ & 5600 \\
\hline MAYO & 33 & $13.26 \%$ & 6500 \\
\hline MEATH & 19 & $9.04 \%$ & 4700 \\
\hline MONAGHAN & 8 & $11.46 \%$ & 2200 \\
\hline OFFALY & 12 & $17.07 \%$ & 4100 \\
\hline ROSCOMMON & 18 & $10.80 \%$ & 2500 \\
\hline SLIGO & 12 & $14.37 \%$ & 3300 \\
\hline TIPPERARY & 25 & $13.36 \%$ & 7200 \\
\hline WATERFORD & 23 & $17.34 \%$ & 6600 \\
\hline WESTMEATH & 16 & $17.43 \%$ & 4600 \\
\hline WEXFORD & 37 & $15.60 \%$ & 7700 \\
\hline WICKLOW & 25 & $18.74 \%$ & 8200 \\
\hline Total & 600 & $12.64 \%$ & 180600 \\
\hline
\end{tabular}

Note: County estimates may not add up exactly to the national total reported in other tables above as in some cases the number sampled within each county are so small that estimates may not be accurate. 


\subsection{Cardiovascular Disease}

Here cardiovascular disease is taken to be at least one of the following: hypertension, heart attack, heart failure or angina. As stated previously, prevalence is calculated based on participants having a history of the disease, not just disease incidence at Wave 5, i.e. we counted disease as being present if the participant reported ever having any of the above medical conditions in any of the TILDA waves (2009-2018) not only if they reported it in 2018 . The population prevalence of CVD was $55.49 \%$, an estimated 802,641 people.

Table 7. Breakdown of number of cases in TILDA, the estimated prevalence (\%) in the population and the estimated number of cases of cardiovascular disease in the population for under and over 70 s

\begin{tabular}{|l|c|c|c|}
\hline CVD by Age & $50-69$ & $70+$ & TOTAL \\
\hline Number Cases in TILDA & 1,120 & 1,595 & 2,715 \\
\hline Estimated Prevalence in Population & $44.72 \%$ & $66.62 \%$ & $55.49 \%$ \\
\hline Estimated Number of Cases in Population & 456202 & 284022 & 802641 \\
\hline
\end{tabular}

Note: The sum over age ranges may not equal total, due to slight inaccuracies in age estimates and rounding errors within age each age range

\subsubsection{Cardiovascular disease by county}

Figure 5. Estimated population prevalence of cardiovascular disease within each county

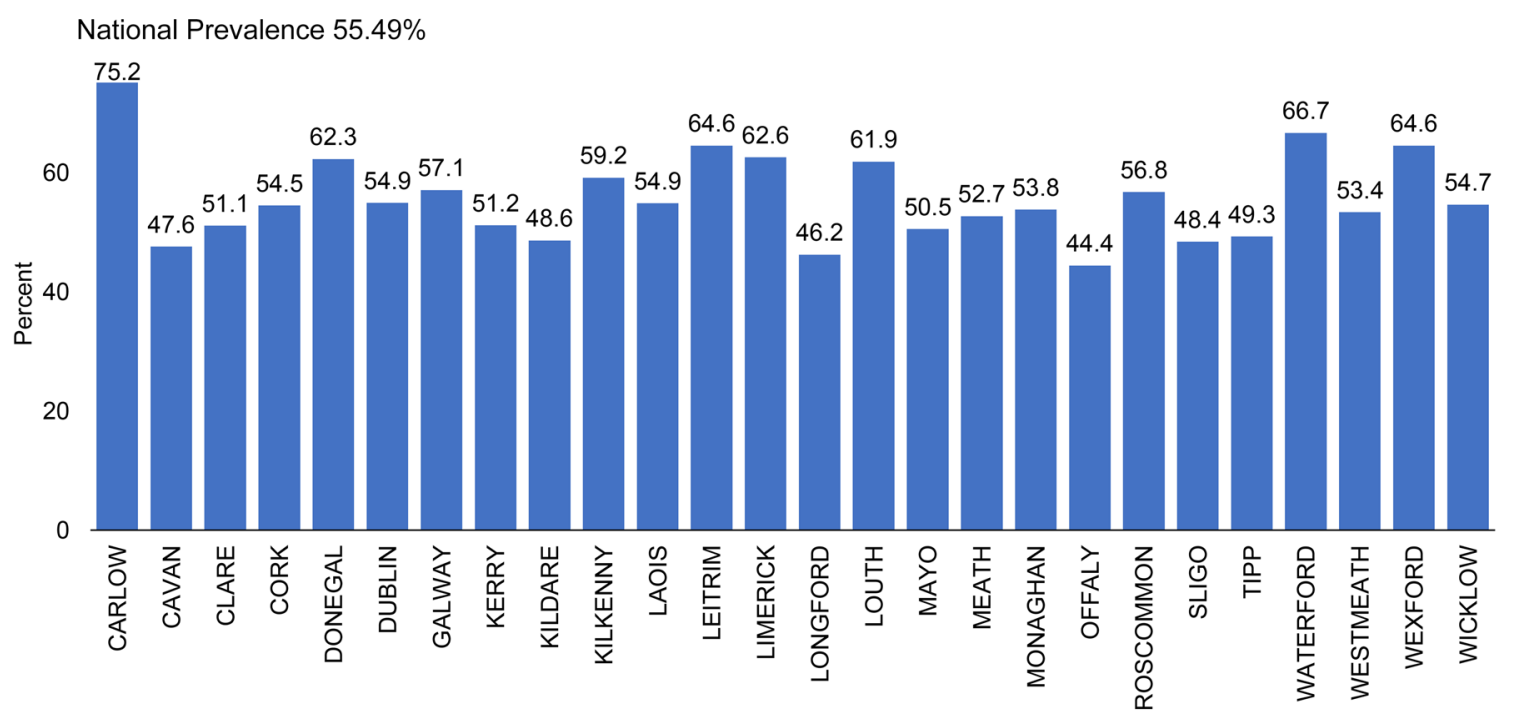


Table 8. Breakdown of number of cases with cardiovascular disease in TILDA, the estimated prevalence (\%) within each county and the estimated number of cases with cardiovascular in the population by county to nearest 100.

\begin{tabular}{|c|c|c|c|}
\hline County & $\begin{array}{c}\text { Number } \\
\text { of TILDA } \\
\text { Cases }\end{array}$ & $\begin{array}{c}\text { County } \\
\text { Prevalence }\end{array}$ & $\begin{array}{l}\text { Estimated } \\
\text { Number in } \\
\text { Population }\end{array}$ \\
\hline CARLOW & 39 & $75.18 \%$ & 12800 \\
\hline CAVAN & 30 & $47.60 \%$ & 11300 \\
\hline CLARE & 59 & $51.11 \%$ & 20300 \\
\hline CORK & 282 & $54.50 \%$ & 91000 \\
\hline DONEGAL & 120 & $62.32 \%$ & 33300 \\
\hline DUBLIN & 636 & $54.94 \%$ & 205700 \\
\hline GALWAY & 153 & $57.09 \%$ & 44900 \\
\hline KERRY & 110 & $51.16 \%$ & 27700 \\
\hline KILDARE & 55 & $48.62 \%$ & 27900 \\
\hline KILKENNY & 57 & $59.18 \%$ & 18900 \\
\hline LAOIS & 28 & $45.88 \%$ & 10700 \\
\hline LEITRIM & 23 & $64.59 \%$ & 7500 \\
\hline LIMERICK & 134 & $62.59 \%$ & 38300 \\
\hline LONGFORD & 22 & $46.24 \%$ & 6000 \\
\hline LOUTH & 53 & $61.86 \%$ & 23000 \\
\hline MAYO & 137 & $50.54 \%$ & 24600 \\
\hline MEATH & 98 & $52.73 \%$ & 27400 \\
\hline MONAGHAN & 45 & $53.82 \%$ & 10400 \\
\hline OFFALY & 38 & $44.41 \%$ & 10800 \\
\hline ROSCOMMON & 85 & $56.77 \%$ & 13200 \\
\hline SLIGO & 41 & $48.41 \%$ & 11200 \\
\hline TIPPERARY & 103 & $49.30 \%$ & 26600 \\
\hline WATERFORD & 95 & $66.70 \%$ & 25600 \\
\hline WESTMEATH & 54 & $53.35 \%$ & 14200 \\
\hline WEXFORD & 139 & $64.60 \%$ & 31700 \\
\hline WICKLOW & 79 & $54.68 \%$ & 24000 \\
\hline Total & 2,715 & $55.49 \%$ & 799100 \\
\hline
\end{tabular}

Note: County estimates may not add up exactly to the national total reported in other tables above as in some cases the number sampled within each county are so small that estimates may not be accurate. 


\subsection{Diabetes and Cardiovascular Disease}

The following shows figures for the co-occurrence of diabetes and cardiovascular disease which has a total prevalence of $9.97 \%$ or an estimated 144,212 people.

Table 9. Breakdown of number of cases in TILDA, the estimated prevalence (\%) in the population and the estimated number of cases of diabetes and cardiovascular disease in the population for under and over 70 s

\begin{tabular}{|l|c|c|c|}
\hline Diabetes and CVD by Age & $50-69$ & $70+$ & TOTAL \\
\hline Number Cases in TILDA & 179 & 294 & 473 \\
\hline Estimated Prevalence in Population & 0.08 & 0.1201 & 0.0997 \\
\hline Estimated Number of Cases in Population & 81610 & 51202 & 144212 \\
\hline
\end{tabular}

Note: The sum over age ranges may not equal total, due to slight inaccuracies in age estimates and rounding errors within age each age range

\subsubsection{Diabetes and Cardiovascular disease by county}

The following shows the prevalence of having both diabetes and cardiovascular disease by county.

Figure 6. Estimated population prevalence of diabetes and cardiovascular disease within each county

National Prevalence $9.97 \%$

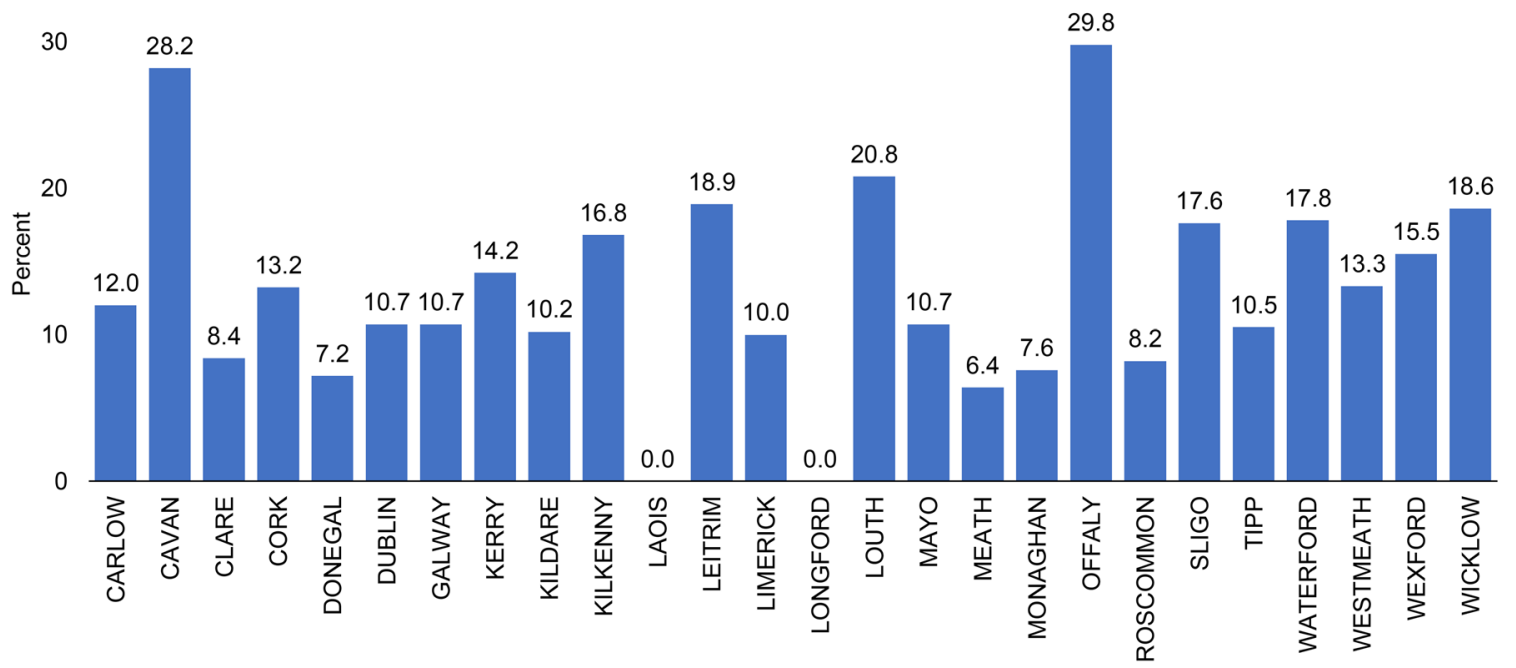


Table 10. Breakdown of number of cases with diabetes and cardiovascular in TILDA, the estimated prevalence (\%) within each county and the estimated number of cases of diabetes and cardiovascular in the population by county to nearest 100.

\begin{tabular}{|c|c|c|c|}
\hline County & $\begin{array}{c}\text { Number } \\
\text { of TILDA } \\
\text { Cases }\end{array}$ & $\begin{array}{c}\text { County } \\
\text { Prevalence }\end{array}$ & $\begin{array}{l}\text { Estimated } \\
\text { Number in } \\
\text { Population }\end{array}$ \\
\hline CARLOW & 8 & $12.00 \%$ & 2800 \\
\hline CAVAN & 6 & $28.20 \%$ & 2800 \\
\hline CLARE & 6 & $8.40 \%$ & 2400 \\
\hline CORK & 44 & $13.20 \%$ & 16500 \\
\hline DONEGAL & 16 & $7.20 \%$ & 3400 \\
\hline DUBLIN & 108 & $10.70 \%$ & 33700 \\
\hline GALWAY & 21 & $10.70 \%$ & 7200 \\
\hline KERRY & 18 & $14.20 \%$ & 6200 \\
\hline KILDARE & 8 & $10.20 \%$ & 2900 \\
\hline KILKENNY & 10 & $16.80 \%$ & 3300 \\
\hline LAOIS & 2 & NA & NA \\
\hline LEITRIM & 4 & $18.90 \%$ & 1800 \\
\hline LIMERICK & 20 & $10.00 \%$ & 6000 \\
\hline LONGFORD & 1 & NA & NA \\
\hline LOUTH & 13 & $20.80 \%$ & 5600 \\
\hline MAYO & 24 & $10.70 \%$ & 4200 \\
\hline MEATH & 18 & $6.40 \%$ & 4700 \\
\hline MONAGHAN & 6 & $7.60 \%$ & 1400 \\
\hline OFFALY & 11 & $29.80 \%$ & 3800 \\
\hline ROSCOMMON & 15 & $8.20 \%$ & 2000 \\
\hline SLIGO & 8 & $17.60 \%$ & 2300 \\
\hline TIPPERARY & 18 & $10.50 \%$ & 5100 \\
\hline WATERFORD & 19 & $17.80 \%$ & 5400 \\
\hline WESTMEATH & 14 & $13.30 \%$ & 4100 \\
\hline WEXFORD & 34 & $15.50 \%$ & 7300 \\
\hline WICKLOW & 21 & $18.60 \%$ & 6800 \\
\hline Total & 473 & $9.97 \%$ & 142300 \\
\hline
\end{tabular}

Note: County estimates may not add up exactly to the national total reported in other tables above as in some cases the number sampled within each county are so small that estimates may not be accurate. 


\subsection{Ischaemic Heart Disease (Myocardial Infarction or angina)}

Table 11. Breakdown of number of cases in TILDA, the estimated prevalence (\%) in the population and the estimated number of cases of ischaemic heart disease in the population for under and over 70 s.

\begin{tabular}{|l|c|c|c|}
\hline Ischaemic Heart Disease by Age & $50-69$ & $70+$ & TOTAL \\
\hline Number Cases in TILDA & 136 & 378 & 514 \\
\hline Estimated Prevalence in Population & $6.08 \%$ & $16.43 \%$ & $11.17 \%$ \\
\hline Estimated Number of Cases in Population & 62024 & 70046 & 161570 \\
\hline
\end{tabular}

Note: The sum over age ranges may not equal total, due to slight inaccuracies in age estimates and rounding errors within age each age range

\subsubsection{Ischaemic heart disease (Myocardial Infarction or angina) disease by county}

Figure 7. Estimated population prevalence of ischaemic heart disease (angina or heart attack) within each county

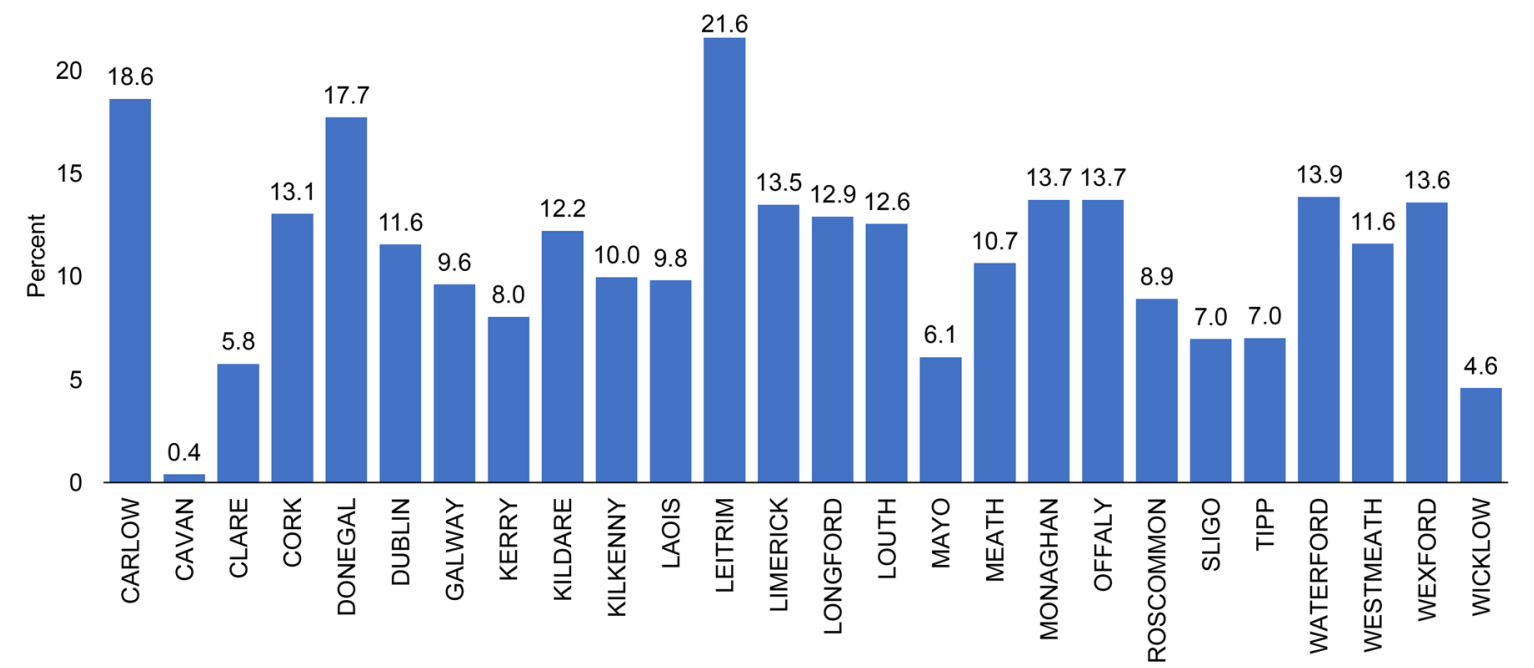


Table 12. Breakdown of number of cases with either ischaemic heart disease in TILDA, the estimated prevalence (\%) within each county and the estimated number of cases of ischaemic heart disease in the population by county to nearest 100

\begin{tabular}{|c|c|c|c|}
\hline County & $\begin{array}{c}\text { Number } \\
\text { of TILDA } \\
\text { Cases }\end{array}$ & $\begin{array}{c}\text { County } \\
\text { Prevalence }\end{array}$ & $\begin{array}{l}\text { Estimated } \\
\text { Number in } \\
\text { Population }\end{array}$ \\
\hline CARLOW & 9 & $18.64 \%$ & 3200 \\
\hline CAVAN & 5 & $8.40 \%$ & 2000 \\
\hline CLARE & 7 & $5.77 \%$ & 2300 \\
\hline CORK & 63 & $13.05 \%$ & 21800 \\
\hline DONEGAL & 31 & $17.74 \%$ & 9500 \\
\hline DUBLIN & 125 & $11.56 \%$ & 43300 \\
\hline GALWAY & 23 & $9.61 \%$ & 7600 \\
\hline KERRY & 18 & $8.04 \%$ & 4400 \\
\hline KILDARE & 11 & $12.22 \%$ & 7000 \\
\hline KILKENNY & 10 & $9.97 \%$ & 3200 \\
\hline LAOIS & 5 & $9.81 \%$ & 2300 \\
\hline LEITRIM & 7 & $21.62 \%$ & 2500 \\
\hline LIMERICK & 23 & $13.50 \%$ & 8300 \\
\hline LONGFORD & 5 & $12.91 \%$ & 1700 \\
\hline LOUTH & 11 & $12.56 \%$ & 4700 \\
\hline MAYO & 22 & $6.10 \%$ & 3000 \\
\hline MEATH & 19 & $10.65 \%$ & 5500 \\
\hline MONAGHAN & 11 & $13.73 \%$ & 2700 \\
\hline OFFALY & 11 & $13.74 \%$ & 3300 \\
\hline ROSCOMMON & 15 & $8.91 \%$ & 2100 \\
\hline SLIGO & 5 & $6.96 \%$ & 1600 \\
\hline TIPPERARY & 15 & $7.01 \%$ & 3800 \\
\hline WATERFORD & 19 & $13.88 \%$ & 5300 \\
\hline WESTMEATH & 9 & $11.59 \%$ & 3100 \\
\hline WEXFORD & 26 & $13.61 \%$ & 6700 \\
\hline WICKLOW & 9 & $4.60 \%$ & 2000 \\
\hline Total & 514 & $11.17 \%$ & 162600 \\
\hline
\end{tabular}

Note: County estimates may not add up exactly to the national total reported in other tables above as in some cases the number sampled within each county are so small that estimates may not be accurate. 


\subsection{Hypertension}

Table 13. Breakdown of number of cases in TILDA, the estimated prevalence (\%) in the population and the estimated number of cases of hypertension in the population for under and over 70s. Note: The sum over age ranges may not equal total, due to slight inaccuracies in age estimates and rounding errors within age each age range

\begin{tabular}{|l|c|c|c|}
\hline Hypertension by Age & $\mathbf{5 0 - 6 9}$ & $\mathbf{7 0 +}$ & TOTAL \\
\hline Number Cases in TILDA & 1,075 & 1,472 & 2,547 \\
\hline Estimated Prevalence in Population & $42.90 \%$ & $61.08 \%$ & $51.84 \%$ \\
\hline Estimated Number of Cases in Population & 437635 & 260403 & 749845 \\
\hline
\end{tabular}

Note: The sum over age ranges may not equal total, due to slight inaccuracies in age estimates and rounding errors within age each age range

\subsubsection{Hypertension by county}

Figure 8. Estimated population prevalence of hypertension within each county

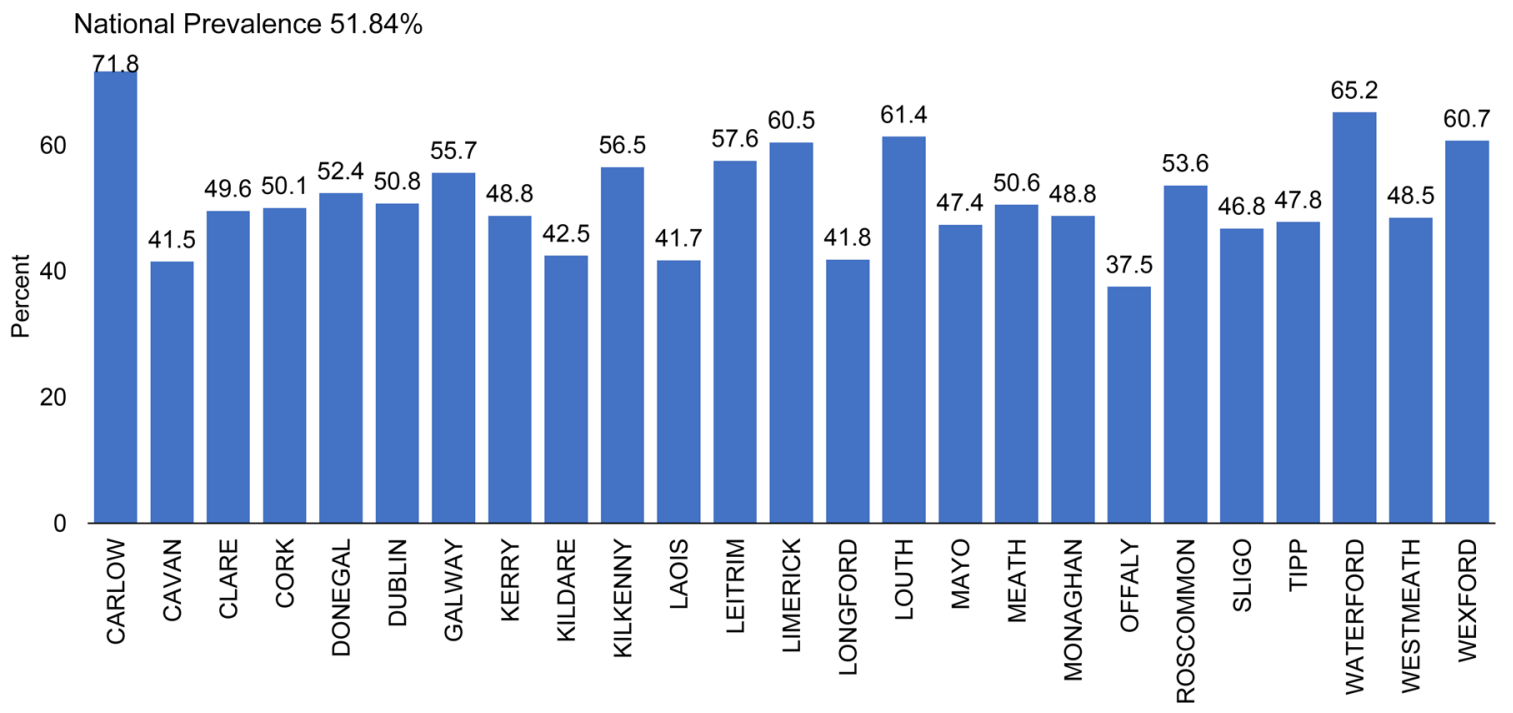


Table 14. Breakdown of number of cases with hypertension in TILDA, the estimated prevalence (\%) within each county and the estimated number of cases of hypertension in the population by county to nearest 100 .

\begin{tabular}{|c|c|c|c|}
\hline County & $\begin{array}{l}\text { Number } \\
\text { of TILDA } \\
\text { Cases }\end{array}$ & $\begin{array}{l}\text { County } \\
\text { Prevalence }\end{array}$ & $\begin{array}{l}\text { Estimated } \\
\text { Number in } \\
\text { Population }\end{array}$ \\
\hline CARLOW & 37 & $71.75 \%$ & 12300 \\
\hline CAVAN & 26 & $41.52 \%$ & 9900 \\
\hline CLARE & 56 & $49.59 \%$ & 19700 \\
\hline CORK & 262 & $50.05 \%$ & 83600 \\
\hline DONEGAL & 105 & $52.41 \%$ & 28000 \\
\hline DUBLIN & 594 & $50.76 \%$ & 190000 \\
\hline GALWAY & 150 & $55.65 \%$ & 43800 \\
\hline KERRY & 104 & $48.80 \%$ & 26400 \\
\hline KILDARE & 51 & $42.47 \%$ & 24400 \\
\hline KILKENNY & 54 & $56.54 \%$ & 18100 \\
\hline LAOIS & 27 & $41.71 \%$ & 9700 \\
\hline LEITRIM & 22 & $57.56 \%$ & 6700 \\
\hline LIMERICK & 127 & $60.47 \%$ & 37000 \\
\hline LONGFORD & 20 & $41.84 \%$ & 5400 \\
\hline LOUTH & 52 & $61.39 \%$ & 22900 \\
\hline MAYO & 129 & $47.63 \%$ & 23200 \\
\hline MEATH & 92 & $50.56 \%$ & 26300 \\
\hline MONAGHAN & 40 & $48.77 \%$ & 9400 \\
\hline OFFALY & 33 & $37.53 \%$ & 9100 \\
\hline ROSCOMMON & 79 & $53.62 \%$ & 12500 \\
\hline SLIGO & 40 & $46.77 \%$ & 10800 \\
\hline TIPPERARY & 100 & $47.81 \%$ & 25800 \\
\hline WATERFORD & 91 & $65.24 \%$ & 25000 \\
\hline WESTMEATH & 50 & $48.52 \%$ & 12900 \\
\hline WEXFORD & 131 & $60.74 \%$ & 29800 \\
\hline WICKLOW & 75 & $52.74 \%$ & 23100 \\
\hline Total & 2,547 & $51.84 \%$ & 745800 \\
\hline
\end{tabular}

Note: County estimates may not add up exactly to the national total reported in other tables above as in some cases the number sampled within each county are so small that estimates may not be accurate. 


\subsection{Rheumatoid Arthritis}

Table 15. Breakdown of number of cases in TILDA, the estimated prevalence (\%) in the population and the estimated number of cases of rheumatoid arthritis in the population for under and over 70 s

\begin{tabular}{|l|c|c|c|}
\hline Rheumatoid Arthritis by Age & $\mathbf{5 0 - 6 9}$ & $\mathbf{7 0 +}$ & TOTAL \\
\hline Number Cases in TILDA & 158 & 230 & 388 \\
\hline Estimated Prevalence in Population & 0.0615 & $10.35 \%$ & $8.22 \%$ \\
\hline Estimated Number of Cases in Population & 105583 & 35044 & 118899 \\
\hline
\end{tabular}

Note: The sum over age ranges may not equal total, due to slight inaccuracies in age estimates and rounding errors within age each age range

\subsubsection{Rheumatoid Arthritis by county}

Figure 9. Estimated population prevalence of rheumatoid arthritis within each county National Prevalence $8.22 \%$

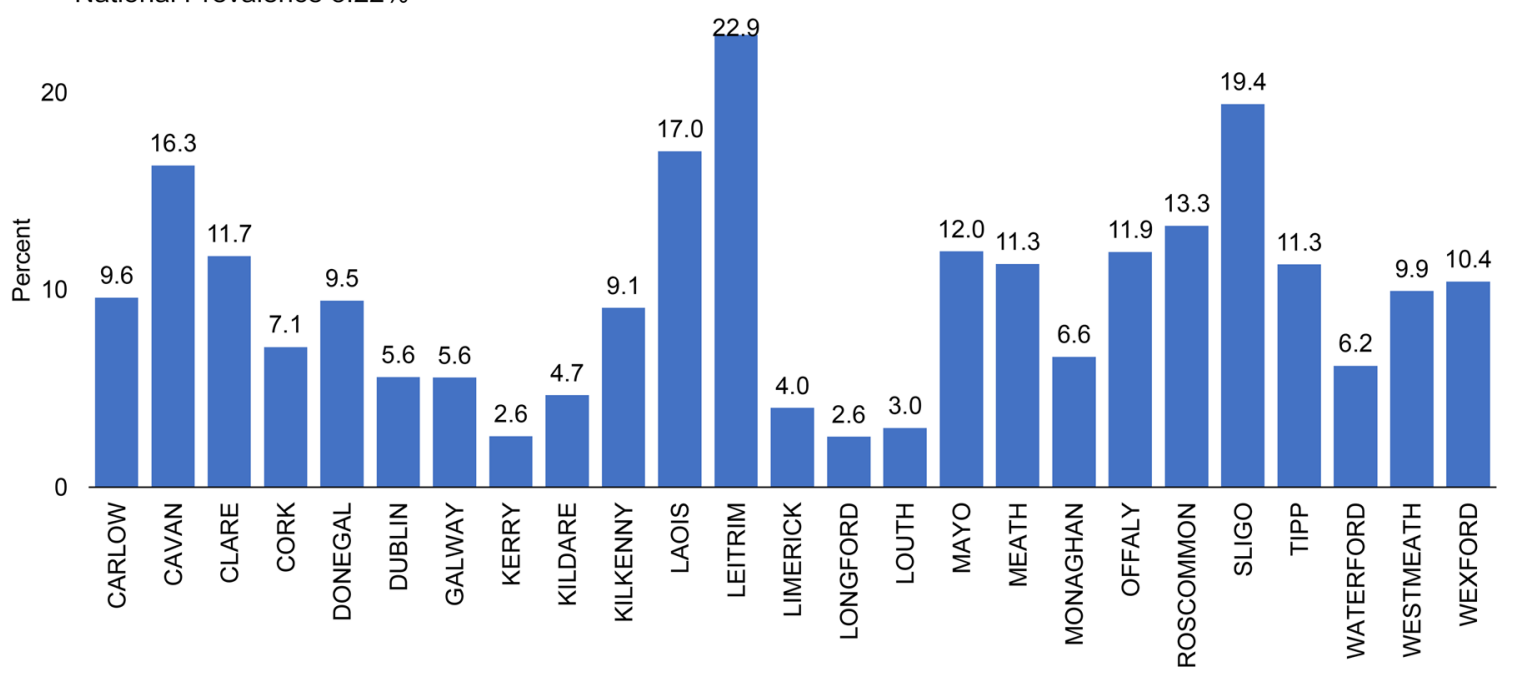


Table 16. Breakdown of number of cases with rheumatoid arthritis in TILDA, the estimated prevalence (\%) within each county and the estimated number of cases of rheumatoid arthritis in the population by county to nearest 100.

\begin{tabular}{|c|c|c|c|}
\hline County & $\begin{array}{c}\text { Number } \\
\text { of TILDA } \\
\text { Cases }\end{array}$ & $\begin{array}{c}\text { County } \\
\text { Prevalence }\end{array}$ & $\begin{array}{l}\text { Estimated } \\
\text { Number in } \\
\text { Population }\end{array}$ \\
\hline CARLOW & 6 & $9.60 \%$ & 1600 \\
\hline CAVAN & 7 & $16.31 \%$ & 3900 \\
\hline CLARE & 13 & $11.72 \%$ & 4700 \\
\hline CORK & 35 & $7.11 \%$ & 11900 \\
\hline DONEGAL & 18 & $9.45 \%$ & 5100 \\
\hline DUBLIN & 58 & $5.59 \%$ & 20900 \\
\hline GALWAY & 19 & $5.56 \%$ & 4400 \\
\hline KERRY & 4 & $2.59 \%$ & 1400 \\
\hline KILDARE & 5 & $4.67 \%$ & 2700 \\
\hline KILKENNY & 9 & $9.08 \%$ & 2900 \\
\hline LAOIS & 9 & $17.03 \%$ & 4000 \\
\hline LEITRIM & 7 & $22.94 \%$ & 2700 \\
\hline LIMERICK & 12 & $4.03 \%$ & 2500 \\
\hline LONGFORD & 3 & $2.56 \%$ & 300 \\
\hline LOUTH & 2 & $3.01 \%$ & 1100 \\
\hline MAYO & 32 & $11.95 \%$ & 5800 \\
\hline MEATH & 21 & $11.31 \%$ & 5900 \\
\hline MONAGHAN & 7 & $6.62 \%$ & 1300 \\
\hline OFFALY & 10 & $11.93 \%$ & 2900 \\
\hline ROSCOMMON & 16 & $13.25 \%$ & 3100 \\
\hline SLIGO & 16 & $19.43 \%$ & 4500 \\
\hline TIPPERARY & 22 & $11.28 \%$ & 6100 \\
\hline WATERFORD & 9 & $6.16 \%$ & 2400 \\
\hline WESTMEATH & 9 & $9.93 \%$ & 2600 \\
\hline WEXFORD & 19 & $10.42 \%$ & 5100 \\
\hline WICKLOW & 20 & $14.13 \%$ & 6200 \\
\hline Total & 388 & $8.22 \%$ & 115800 \\
\hline
\end{tabular}

Note: County estimates may not add up exactly to the national total reported in other tables above as in some cases the number sampled within each county are so small that estimates may not be accurate. 


\subsection{Chronic Kidney Disease*}

Data for chronic kidney disease (CKD) were only available for Wave 1 (data collected 2009-2010) and so estimates for CKD are based on the 2011 Census*.

Table 17. Breakdown of number of cases in TILDA, the estimated prevalence (\%) in the population and the estimated number of cases of chronic kidney disease ${ }^{*}$ in the population for under and over 70s

\begin{tabular}{|l|c|c|c|}
\hline CKD by Age & $50-69$ & $70+$ & TOTAL \\
\hline Number Cases in TILDA & 212 & 216 & 428 \\
\hline Estimated Prevalence in Population & $5.74 \%$ & $28.03 \%$ & $10.10 \%$ \\
\hline Estimated Number of Cases in Population & 255446 & 36537 & 128582 \\
\hline
\end{tabular}

Note: The sum over age ranges may not equal total, due to slight inaccuracies in age estimates and rounding errors within age each age range

${ }^{*}$ Chronic kidney disease was estimated from blood samples for creatine and consequently glomerular filtration rates

\subsubsection{Chronic Kidney Disease by county}

Figure 10: Estimated population prevalence of chronic kidney disease within each county National Prevalence $8.22 \%$

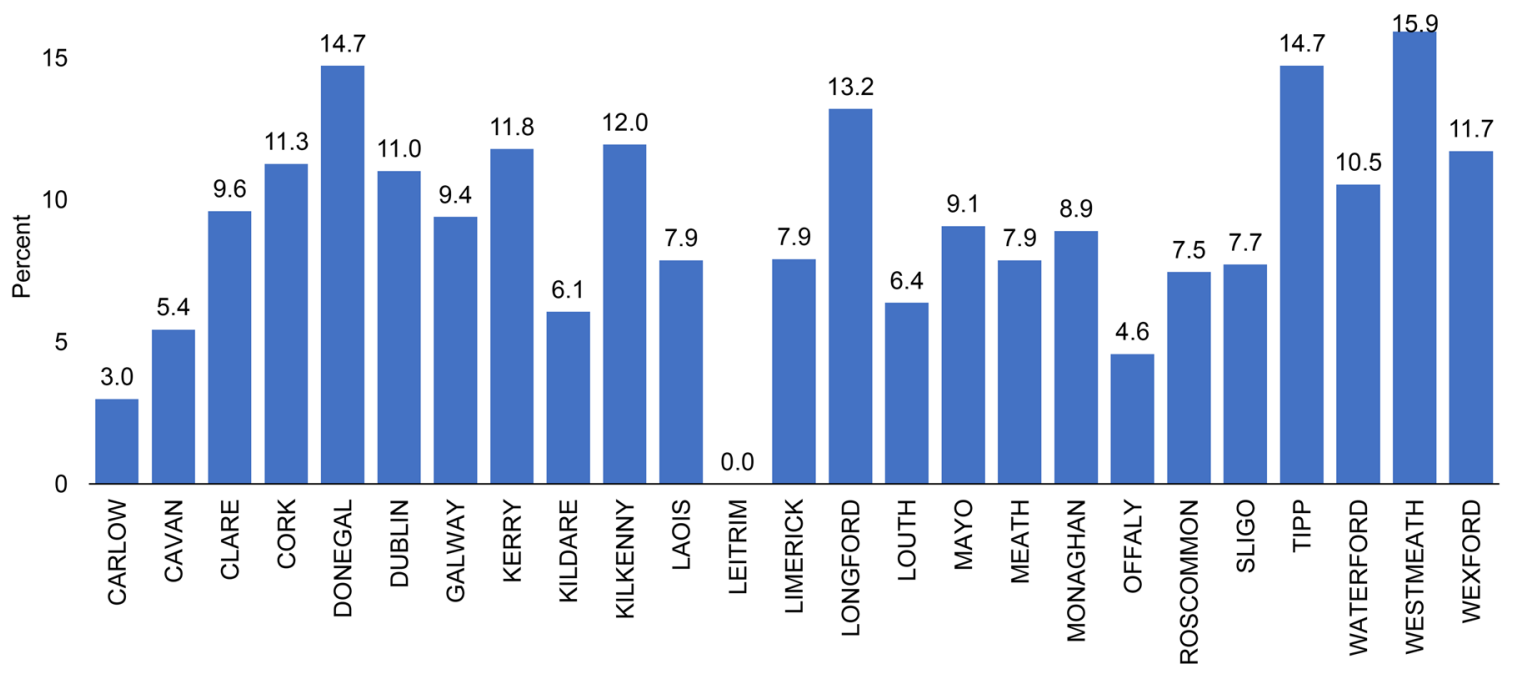


Table 18. Breakdown of number of cases with chronic kidney disease in TILDA, the estimated prevalence (\%) within each county and the estimated number of chronic kidney disease or asthma in the population by county to nearest 100.

\begin{tabular}{|c|c|c|c|}
\hline County & $\begin{array}{c}\text { Number } \\
\text { of TILDA } \\
\text { Cases }\end{array}$ & $\begin{array}{c}\text { County } \\
\text { Prevalence }\end{array}$ & $\begin{array}{l}\text { Estimated } \\
\text { Number in } \\
\text { Population }\end{array}$ \\
\hline CARLOW & 1 & $2.99 \%$ & 400 \\
\hline CAVAN & 3 & $5.44 \%$ & 1100 \\
\hline CLARE & 9 & $9.60 \%$ & 3400 \\
\hline CORK & 56 & $11.27 \%$ & 16500 \\
\hline DONEGAL & 15 & $14.72 \%$ & 7100 \\
\hline DUBLIN & 134 & $11.02 \%$ & 36300 \\
\hline GALWAY & 21 & $9.40 \%$ & 6500 \\
\hline KERRY & 24 & $11.79 \%$ & 5700 \\
\hline KILDARE & 6 & $6.05 \%$ & 2900 \\
\hline KILKENNY & 10 & $11.95 \%$ & 3300 \\
\hline LAOIS & 3 & $7.87 \%$ & 1600 \\
\hline LEITRIM & 0 & $0.00 \%$ & 0 \\
\hline LIMERICK & 15 & $7.91 \%$ & 4400 \\
\hline LONGFORD & 3 & $13.20 \%$ & 1500 \\
\hline LOUTH & 4 & $6.37 \%$ & 2100 \\
\hline MAYO & 16 & $9.08 \%$ & 4000 \\
\hline MEATH & 14 & $7.87 \%$ & 3400 \\
\hline MONAGHAN & 5 & $8.90 \%$ & 1600 \\
\hline OFFALY & 3 & $4.58 \%$ & 1000 \\
\hline ROSCOMMON & 7 & $7.45 \%$ & 1600 \\
\hline SLIGO & 7 & $7.72 \%$ & 1600 \\
\hline TIPPERARY & 22 & $14.73 \%$ & 7200 \\
\hline WATERFORD & 13 & $10.54 \%$ & 3600 \\
\hline WESTMEATH & 12 & $15.93 \%$ & 3700 \\
\hline WEXFORD & 18 & $11.72 \%$ & 5000 \\
\hline WICKLOW & 7 & $5.94 \%$ & 2200 \\
\hline Total & 428 & $10.10 \%$ & 127800 \\
\hline
\end{tabular}

Note: County estimates may not add up exactly to the national total reported in other tables above as in some cases the number sampled within each county are so small that estimates may not be accurate. 


\subsection{Smoking History}

Table 19. Estimated number of population by county who have never smoked, are former smokers or are current smokers (as of 2018) to the nearest 100

\begin{tabular}{|l|c|c|c|c|}
\hline County & Never & Former & Current & Total \\
\hline CARLOW & 7200 & 7300 & 2500 & 17100 \\
\hline CAVAN & 9700 & 11500 & 2600 & 23800 \\
\hline CLARE & 22500 & 15500 & 1700 & 39800 \\
\hline CORK & 76100 & 68800 & 22000 & 167000 \\
\hline DONEGAL & 21400 & 24700 & 7400 & 53500 \\
\hline DUBLIN & 156000 & 176000 & 42300 & 374400 \\
\hline GALWAY & 38000 & 32800 & 7800 & 78700 \\
\hline KERRY & 22000 & 22300 & 9800 & 54100 \\
\hline KILDARE & 20100 & 30100 & 7200 & 57400 \\
\hline KILKENNY & 11200 & 16900 & 3800 & 31900 \\
\hline LAOIS & 11500 & 11100 & 800 & 23400 \\
\hline LEITRIM & 4500 & 5900 & 1300 & 11700 \\
\hline LIMERICK & 28600 & 25600 & 7000 & 61200 \\
\hline LONGFORD & 4900 & 5200 & 2800 & 12900 \\
\hline LOUTH & 17600 & 15800 & 3900 & 37200 \\
\hline MAYO & 20100 & 23600 & 5100 & 48700 \\
\hline MEATH & 22700 & 24300 & 4900 & 51900 \\
\hline MONAGHAN & 11200 & 5800 & 2300 & 19300 \\
\hline OFFALY & 9800 & 9900 & 4700 & 24300 \\
\hline ROSCOMMON & 13800 & 5300 & 4200 & 23300 \\
\hline SLIGO & 931600 & 641800 & 173000 & 1446400 \\
\hline TIPPERARY & 23200 & 23700 & 7100 & 53900 \\
\hline WATERFORD & 15300 & 17700 & 5300 & 38300 \\
\hline WESTMEATH & 13700 & 10400 & 2500 & 26600 \\
\hline WEXFORD & 20200 & 20600 & 8200 & 49000 \\
\hline WICKLOW & & & & 23100 \\
\hline Total & 11600 & 2500 & \\
\hline
\end{tabular}




\section{Medications Data}

This section will show the breakdown of numbers of over 50 s at Wave 5 (2018) using the following medications (identified using WHO Anatomical Therapeutic Chemical (ATC) codes https://www.whocc.no/atc ddd index/):

- Any blood glucose lowering drug ${ }^{1}$

- Thiazolidinediones

- Antihypertensives ${ }^{2}$

- ACE Inhibitors ${ }^{3}$

- Angiotensin II Antagonists ${ }^{3}$

- Oral Ibuprofen

- Inhaled corticosteroid

- Topical corticosteroid

- Immunosuppressants

- Antineoplastic agents

These estimates are based on participants reporting of medications that they take at the time of Wave 5 data collection on a regular basis, live every day or every week. They are asked to report not just prescription medications, but also over-the-counter medications and supplements. The data may underestimate exposure to medications used intermittently, such as ibuprofen in this case, where participant may only have reported this if they use it regularly.

1 This includes insulin and its analogues, and other oral and non-oral blood glucose lowering drugs. This corresponds to ATC code A10.

2 This includes diuretics, beta blockers, calcium channel blockers, ACE inhibitors, Angiotensin II Antagonists, other Renin-Angiotensin System agents, and other antihypertensives. This corresponds to ATC codes C02, C03, C0, C08, and C09.

3 This includes both single ingredient and fixed-dose combination medications. 


\subsection{Blood Glucose Lowering Drug}

Table 20. Breakdown of number of cases in TILDA, the estimated prevalence (\%) in the population and the estimated number of cases taking any blood glucose lowering drug in the population for under and over 70 s

\begin{tabular}{|l|c|c|c|}
\hline Any blood glucose lowering drug & $50-69$ & $70+$ & TOTAL \\
\hline Number Cases in TILDA & 179 & 269 & 448 \\
\hline Estimated Prevalence in Population & $3.78 \%$ & $5.38 \%$ & $9.16 \%$ \\
\hline Estimated Number of Cases in Population & 38561 & 22937 & 132496 \\
\hline
\end{tabular}

Note: The sum over age ranges may not equal total, due to slight inaccuracies in age estimates and rounding errors within age each age range

\subsection{Thiazolidinedione}

Table 21. Breakdown of number of cases in TILDA, the estimated prevalence (\%) in the population and the estimated number of cases taking thiazolidinediones in the population for under and over 70s

\begin{tabular}{|l|c|c|c|}
\hline Thiazolidinedione & $50-69$ & $70+$ & TOTAL \\
\hline Number Cases in TILDA & 4 & 5 & 9 \\
\hline Estimated Prevalence in Population & $0.23 \%$ & $0.17 \%$ & $0.20 \%$ \\
\hline Estimated Number of Cases in Population & 2346 & 725 & 2893 \\
\hline
\end{tabular}

Note: The sum over age ranges may not equal total, due to slight inaccuracies in age estimates and rounding errors within age each age range

\subsection{Antihypertensives}

Table 22. Breakdown of number of cases in TILDA, the estimated prevalence (\%) in the population and the estimated number of cases taking any antihypertensives in the population for under and over 70 s

\begin{tabular}{|l|c|c|c|}
\hline Taking any antihypertensives & $\mathbf{5 0 - 6 9}$ & $\mathbf{7 0 +}$ & TOTAL \\
\hline Number Cases in TILDA & 920 & 1,482 & 2,402 \\
\hline Estimated Prevalence in Population & $36.37 \%$ & $62.8 \%$ & $49.35 \%$ \\
\hline Estimated Number of Cases in Population & 371021 & 267736 & 713828 \\
\hline
\end{tabular}

Note: The sum over age ranges may not equal total, due to slight inaccuracies in age estimates and rounding errors within age each age range 


\subsection{Angiotensin II Antagonist}

Table 23. Breakdown of number of cases in TILDA, the estimated prevalence (\%) in the population and the estimated number of cases taking any angiotensin II antagonists in the population for under and over 70 s

\begin{tabular}{|l|c|c|c|}
\hline Any Angiotensin II Antagonist & $50-69$ & $70+$ & TOTAL \\
\hline Number Cases in TILDA & 279 & 465 & 744 \\
\hline Estimated Prevalence in Population & $11.04 \%$ & $19.26 \%$ & $15.08 \%$ \\
\hline Estimated Number of Cases in Population & 112622 & 82111 & 218126 \\
\hline
\end{tabular}

Note: The sum over age ranges may not equal total, due to slight inaccuracies in age estimates and rounding errors within age each age range

\subsection{Oral Ibuprofen}

Table 24. Breakdown of number of cases in TILDA, the estimated prevalence (\%) in the population and the estimated number of cases taking any oral ibuprofen in the population for under and over 70 s

\begin{tabular}{|l|c|c|c|}
\hline Any Angiotensin II Antagonist & $\mathbf{5 0 - 6 9}$ & $\mathbf{7 0 +}$ & TOTAL \\
\hline Number Cases in TILDA & 32 & 16 & 48 \\
\hline Estimated Prevalence in Population & $1.47 \%$ & $0.62 \%$ & $1.05 \%$ \\
\hline Estimated Number of Cases in Population & 14996 & 2643 & 15188 \\
\hline
\end{tabular}

Note: The sum over age ranges may not equal total, due to slight inaccuracies in age estimates and rounding errors within age each age range 


\subsection{Oral or Inhaled Corticosteroid}

Table 25. Breakdown of number of cases in TILDA, the estimated prevalence (\%) in the population and the estimated number of cases of taking any oral corticosteroid in the population for under and over 70 s

\begin{tabular}{|l|c|c|c|}
\hline Any Oral Corticosteroid & $50-69$ & $70+$ & TOTAL \\
\hline Number Cases in TILDA & 14 & 12 & 26 \\
\hline Estimated Prevalence in Population & $0.54 \%$ & $0.49 \%$ & $0.51 \%$ \\
\hline Estimated Number of Cases in Population & 5509 & 2302 & 7088 \\
\hline
\end{tabular}

Note: The sum over age ranges may not equal total, due to slight inaccuracies in age estimates and rounding errors within age each age range

Table 26. Breakdown of number of cases in TILDA, the estimated prevalence (\%) in the population and the estimated number of cases taking any inhaled corticosteroid in the population for under and over 70s

\begin{tabular}{|l|c|c|c|}
\hline Any Inhaled Corticosteroid & $\mathbf{5 0 - 6 9}$ & $\mathbf{7 0 +}$ & TOTAL \\
\hline Number Cases in TILDA & 79 & 46 & 125 \\
\hline Estimated Prevalence in Population & $2.96 \%$ & $2.20 \%$ & $2.59 \%$ \\
\hline Estimated Number of Cases in Population & 30196 & 12619 & 31822 \\
\hline
\end{tabular}

Note: The sum over age ranges may not equal total, due to slight inaccuracies in age estimates and rounding errors within age each age range 


\subsection{Immunosuppressant}

Table 27. Breakdown of number of cases in TILDA, the estimated prevalence (\%) in the population and the estimated number of cases taking any immunosuppressant in the population for under and over 70 s

\begin{tabular}{|l|c|c|c|}
\hline Any Immunosuppressant & $\mathbf{5 0 - 6 9}$ & $\mathbf{7 0 +}$ & TOTAL \\
\hline Number Cases in TILDA & 27 & 13 & 40 \\
\hline Estimated Prevalence in Population & $0.91 \%$ & $0.52 \%$ & $0.72 \%$ \\
\hline Estimated Number of Cases in Population & 5305 & 2217 & 10415 \\
\hline
\end{tabular}

Note: The sum over age ranges may not equal total, due to slight inaccuracies in age estimates and rounding errors within age each age range

\subsection{Antineoplastic Agent}

Table 28. Breakdown of number of cases in TILDA, the estimated prevalence (\%) in the population and the estimated number of cases taking any antineoplastic agent in the population for under and over 70 s

\begin{tabular}{|l|c|c|c|}
\hline Taking any Antineoplastic Agent & $50-69$ & $70+$ & TOTAL \\
\hline Number Cases in TILDA & 12 & 8 & 20 \\
\hline Estimated Prevalence in Population & $0.49 \%$ & $0.34 \%$ & $0.42 \%$ \\
\hline Estimated Number of Cases in Population & 3468 & 1450 & 6075 \\
\hline
\end{tabular}

Note: The sum over age ranges may not equal total, due to slight inaccuracies in age estimates and rounding errors within age each age range

\subsection{Topical Corticosteroid}

Table 29. Breakdown of number of cases in TILDA, the estimated prevalence (\%) in the population and the estimated number of cases using any topical corticosteroid in the population for under and over 70 s

\begin{tabular}{|l|c|c|c|}
\hline Using any Topical Corticosteroid & $50-69$ & $70+$ & TOTAL \\
\hline Number Cases in TILDA & 12 & 8 & 20 \\
\hline Estimated Prevalence in Population & $0.49 \%$ & $0.34 \%$ & $0.42 \%$ \\
\hline Estimated Number of Cases in Population & 3468 & 1450 & 6075 \\
\hline
\end{tabular}

Note: The sum over age ranges may not equal total, due to slight inaccuracies in age estimates and rounding errors within age each age range 


\section{Conclusions}

High-risk categories for COVID-19 and their distribution by county in Republic of Irelandevidence from the TILDA study ", gives the estimated number of people over 50 in Ireland and by county who have diabetes, cardiovascular disease, ischaemic heart disease, lung disease or asthma, rheumatoid arthritis, chronic kidney disease and a history of smoking; all of which are medical conditions/behaviours suspected to be risk factors for more severe symptoms of COVID-19. It also looks at comorbidities, or the presence of two or more chronic conditions.

Among its findings are:

- Almost 750,000 adults over 50 , and 260,000 adults over 70 have hypertension

- 182,000 adults over 50 , and 80,000 adults over 70 have asthma

- 183,000 adults over 50 , and 63,000 adults over 70 have diabetes mellitus

- 129,000 adults over 50 , and 36,000 adults over 70 have chronic kidney disease

- 167,500 adults over 50 , and 99,000 adults over 70 have past or present cancer

- 123,000 Adults over 50 , and 65,000 adults over 70 have chronic lung disease

- Over 377,000 adults over 50, and 91,000 adults over 70 live with two comorbidities

- 637,000 adults over 50 , and 260,000 adults over 70 live with three or more comorbidities

An unprecedented crisis like the COVID-19 pandemic can pose serious health risks for older populations. This report aims to inform Government, the HSE and public about the prevalence in Ireland, nationally and by county, of a range of conditions and of medication usage which have been identified as possible risk factors associated with COVID-19. The challenges the pandemic poses to our health system and society are apparent; this is one of a suite of TILDA reports detailing the prevalence of risk factors and rates of use of health and community services among the older population in Ireland, which will assist in the planning and delivery of supports and services. 


\section{References}

1. Kenny RA, Hernández B, O'Halloran A, Moriarty F, McGarrigle C. TILDA Report to inform demographics for over 50s in Ireland for covid19 crisis https://www. doi. org/10.38018/TildaRe.2020-00

2. Whelan BJ, Savva GM. Design and methodology of the Irish Longitudinal Study on Ageing. Journal of the American Geriatrics Society. 2013 May;61:S265-8.

3. Whelan BJ. Ransam a random sample design for Ireland. Economic and Social Review. 1979;10(2):169.

4. Cronin H, O'Regan C, Finucane C, Kearney P, Kenny RA. Health and aging: development of the Irish Longitudinal Study on Ageing health assessment. Journal of the American Geriatrics Society. 2013 May;61:S269-78. 